\title{
Sedimentary sequences on the offshore southern region of the Sergipe-Alagoas Basin
}

Matheus Rodrigues Cunha* (IG/UnB), Marcelo Peres Rocha (IG/UnB)

Copyright 2019, SBGf - Sociedade Brasileira de Geofísica

This paper was prepared for presentation during the $16^{\text {th }}$ International Congress of the Brazilian Geophysical Society held in Rio de Janeiro, Brazil, 19-22 August 2019.

Contents of this paper were reviewed by the Technical Committee of the $16^{\text {th }}$ International Congress of the Brazilian Geophysical Society and do not necessarily represent any position of the SBGf, its officers or members. Electronic reproduction or storage of any part of this paper for commercial purposes without the written consent of the Brazilian Geophysical Society is prohibited.

\section{Abstract}

The seismic processing flow varies according to the studied region and which medium properties it presents. In this work we processed a pre-stack seismic line on the southern area of the Sergipe-Alagoas basin, and used a well at the same place to verify the interpretation. The line was subjected to a true amplitude process, as later it would be used for amplitude analysis. The processing included predictive deconvolution, parabolic radon and Prestack Time Migration. The velocity model generated at the velocity analysis was improved after the Prestack Time Migration. From the stacked section, the Rift and Marine Regressive Sequences were identified, assisted by the interpretation of the well, which was previously done.

\section{Introduction}

The Sergipe-Alagoas basin (Figure 1) is a sedimentary basin on Northeast Brazil and has been a subject of many studies since the 60's, due to its oil and gas reservoirs. Thus, there is a large variety of seismic and well data on the basin. Despite being a well know basin, there is still place for new information share, partially because some of this knowledge is retained at the companies.

The basin has a total area of $53000 \mathrm{~km}^{2}$, in which 13000 $\mathrm{km}^{2}$ are onshore and $40000 \mathrm{~km}^{2}$ offshore. The SergipeAlagoas name refers to the two sub-basins: Sergipe and Alagoas. It is divided in 5 groups: Igreja Nova, Perucaba, Coruripe, Sergipe and Piaçabuçu; or according to the Supersequences: Paleozoic, Prerift, Rift, Postrift and Drift (Schaller, 1969; Van Der Ven et al., 1989; Feijó, 1994; Campos Neto et al., 2007).

The origin of the basin is connected to the South Atlantic Ocean opening, and the Supersequences also indicate the five stages of the Gondwana continental break-up (Cainelli e Mohriak, 1999), which posteriorly became South America and Africa.

The Igreja Nova group is related to the Paleozoic Supersequence, which is connected to early stages of the development. The Supersequence Prerift comprises the Perucaba group, and the deposition happened from the Upper Jurassic to the Lower Cretaceous (Van Der Ven et al., 1989). The Rift Supersequence includes the Coruripe group. The rifting process began at the Berriasian and finished at the Aptian (Campos Neto et al., 2007), with a fault system with N-S and E-W directions (Van Der Ven et al., 1989).

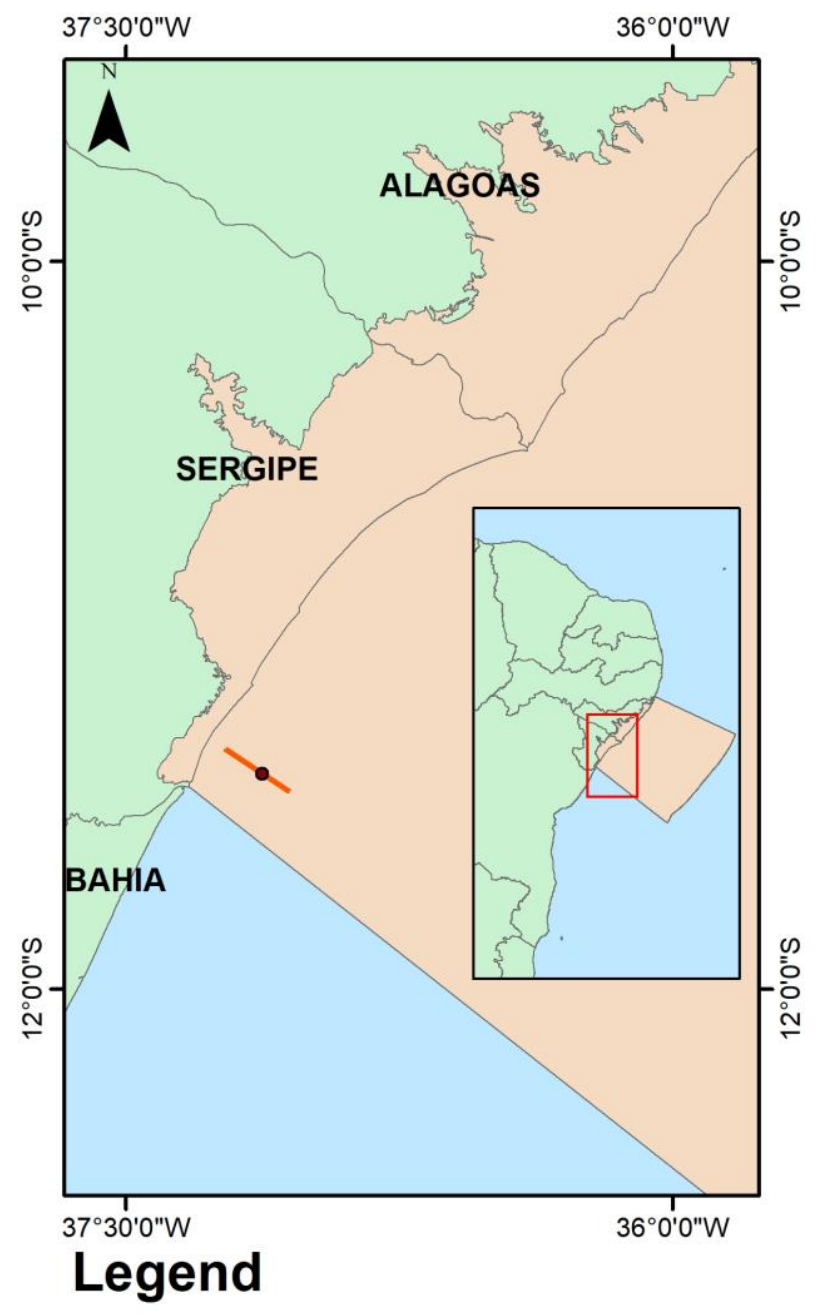

- Well

\section{Seismic Line}

\section{Sergipe-Alagoas Basin}

Figure 1 - Localization of the seismic line and the well. Those are placed on the Sergipe-Alagoas basin, in Northeast Brazil.

The Drift Supersequence contains the deposition of two groups, Sergipe and Piaçabuçu, mainly composed by carbonates due to a thermal subsidence that was initiated at the Albian (Van Der Ven et al., 1989).

Although the basin is geologically well documented, there are still local variations inside, as it is not entirely homogeneous. The objective of this work was to show not 
only the true amplitude seismic processing applied, which will allow later to perform amplitude analysis on the seismic line, but also the stratigraphic sequences and how the sediments were deposited on the south of basin.

\section{Method}

The seismic line (Table 1) used was acquired in 1996 by Petrobras, on the continental shelf, with a NE-SW direction. The data belongs to Agency of Petroleum, Natural Gas and Biofuels (ANP), and the use of this data was possible due to a partnership with the Geotechnics Laboratory of the University of Brasilia.

Table 1 - Acquisition parameters of the seismic line

\begin{tabular}{|cc|}
\hline Extension & $23.125 \mathrm{~km}$ \\
Source spacing & $25 \mathrm{~m}$ \\
Receiver spacing & $12.5 \mathrm{~m}$ \\
Distance between source and streamer & $160 \mathrm{~m}$ \\
Maximum offset & $3172.5 \mathrm{~m}$ \\
Streamer extension & $3025 \mathrm{~m}$ \\
Number of traces & 242 \\
Sampling & $2 \mathrm{~ms}$ \\
Shot number & 915 \\
\hline
\end{tabular}

As the navigation file contained only the source positions, the receiver interval was estimated measuring the time difference of the first arrival of two sequential traces, with a $P$ wave velocity of $1500 \mathrm{~m} / \mathrm{s}$ (at water), which led to a spacing of $12.5 \mathrm{~m}$. Similarly, the first offset was calculated with the time of the direct wave arrival at the first trace, and the same velocity, resulting in a distance of $160 \mathrm{~m}$.

The processing (Figure 2) was performed mainly in Seismic Unix (Cohen e Stockwell, 2013) and a few parts in Madagascar (Fomel et al., 2013). Both are free software.

The sampling time was reduced from $2 \mathrm{~ms}$ to $4 \mathrm{~ms}$. The frequency spectra indicated that the frequency content wouldn't be trimmed, so in order to save storage space and increase processing time, the sampling was decreased. Also, it was applied a bandpass filter to remove the low and high frequency noise.

Sequentially, it was designed a mute to remove the direct wave. As the acquisition was done on shallow waters, there was a significant amount of this type of noise for the earlier times.

It was applied a predictive deconvolution (Figure 3) to remove the water bottom multiples and other repeatable multiples. The parameters were obtained from an autocorrelation window. The predictive deconvolution (Peacock e Treitel, 1969) is based on the attenuation of signals that repeat itself though the seismogram, therefore they are predictable, and can be attenuated.

A parabolic radon transform (Hampson, 1986) was applied, to remove remaining multiples, especially at later times. The parabolic radon transform adjusts hyperbolas though the parameters of curvature and intercept time.

Thus, it is applied an NMO correction with a velocity curve chosen, so that the events of interest are curved upwards, and the multiples curved downwards. In the radon domain, all events with downwards hyperbolas are removed, and the data is transformed back to the timespace domain.

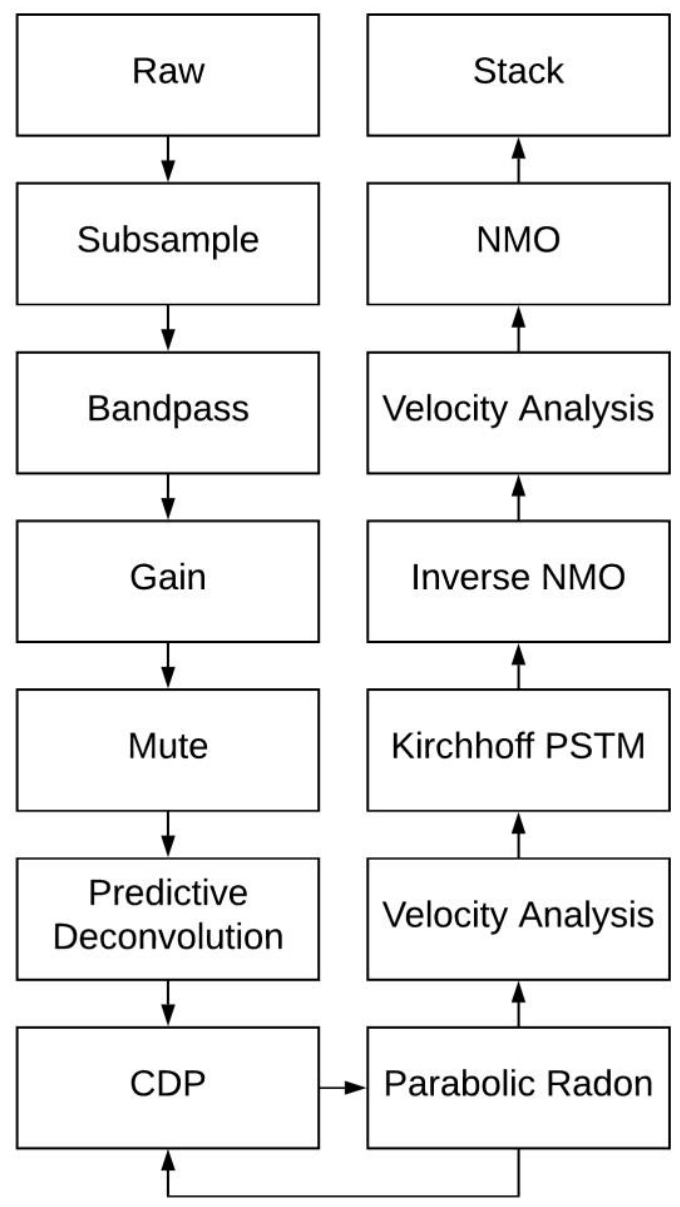

Figure 2 - Flowchart with the steps used in the processing of the seismic line.

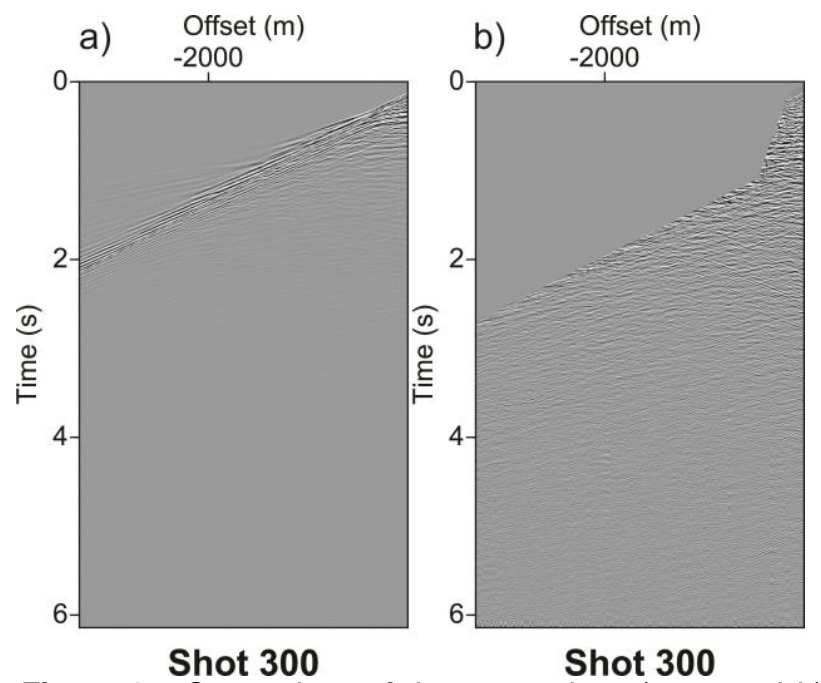

Figure 3 - Comparison of the same shot a) raw and b) until the predictive deconvolution, according to the flow in Figure 2. 
The parabolic radon was performed twice. A first time, $\mathrm{NMO}$ corrected with the water velocity of $1500 \mathrm{~m} / \mathrm{s}$, to remove the water bottom multiples and low velocity noise and thus chose a velocity curve for the second apply of the radon. The second time, the same entry data for the first radon was NMO corrected with a velocity curve between the multiples and primaries velocities, and then the radon was applied (Figure 4). It was done twice to preserve the signals, knowing that no velocity was below the water velocity.
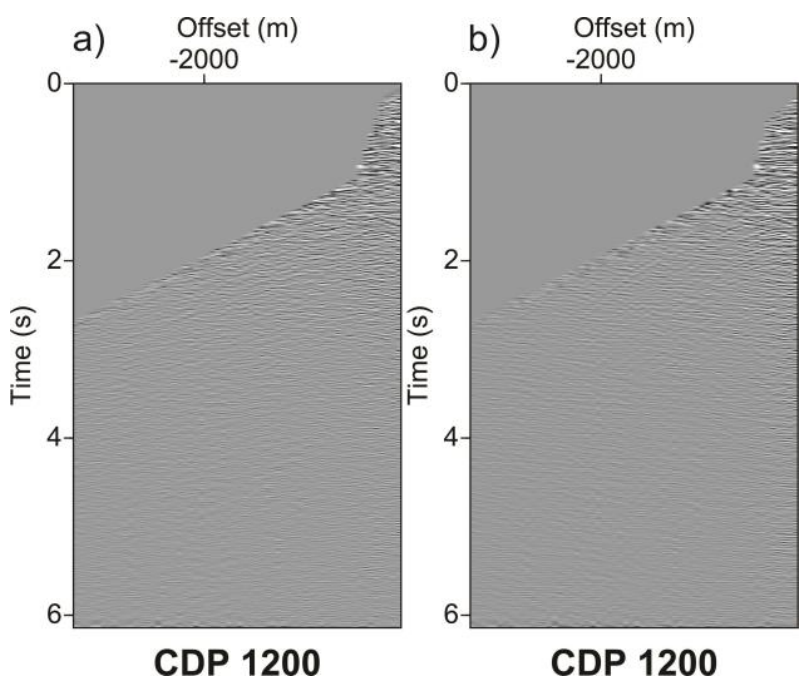

Figure 4 - Same CDP comparison a) before and b) after the parabolic radon.

In the velocity analysis, a Madagascar's automate picking tool allowed to inspect the semblance panel generated for each individual CDP (Figure 5).

A Kirchhoff Prestack Time Migration (PSTM) was applied with the velocity model generated from the velocity analysis. This migration is used to solve dip issues and lateral velocity variations. From the migrated gathers, a new velocity analysis was performed, which generated a new velocity model.

After all the processing steps were accomplished, the image gathers were stacked to generate the stacked section, which is going to be interpreted.

\section{Results}

Based on a previous interpretation of the well close to the seismic line, the generated stacked section was interpreted, and the main sequences were delimited.

The velocity model at Figure 5 presents the difference between the velocity analysis before and after the PSTM. In both models, there are mainly three regions, with different characteristic velocities: a first represented mainly by the bluish colors; a second represented by greenish colors; and a third with orange colors. In the model before the PSTM, these regions slightly tilt as the CDP number increases, while in the model after the PSTM, the regions are flatter, and the slope is better defined.
The stacked section at Figure 6 already presents the interpretation. The first interface is the ocean bottom, successively followed by the sediments of the Regressive Marine Sequence, Rift Sequence and the Basement rocks.

The basement is limited by a strong reflection. Around the middle of the section, the reflected energy decreases significantly, making it difficult to follow this interface.

According to Cruz et al. (2010), the main stratigraphic sequences above the basement at the Sergipe-Alagoas Basin on the continental shelf are the Prerift, Transitional, Marine Transgressive and Marine Regressive.

Above the basement is the Rift Sequence. In this case, they are composed by the Barra de Itiúba and Penedo Formations. The well indicate that there wasn't found any rock related to Transitional Sequence, and neither to the Marine Transgressive, as after the Penedo Formation are the shales of the Calumbi Formation.

This result is not unexpected, as the seismic line position is at the end of the continental shelf and towards the slope, where the Transitional and Transgressive Sequences thin.

\section{Conclusions}

The processing of the data was partially successful, as it attenuated the multiples on the profile, except at the slope where they are still present.

The velocity model suffered an improvement after the PSTM, that match the interfaces better, especially at the slope.

The stacked section allowed the identification of the Rift Sequence and the Marine Transgressive Sequence, and there is not any indication of a sequence related to the sea level rise.

\section{Acknowledgments}

The authors would like to thank the ANP for providing the seismic data, as well the Geotechnics Laboratory of the University of Brasilia.

\section{References}

Cainelli, C., Mohriak, W.U., 1999. Some remarks on the evolution of sedimentary basins along the eastern Brazilian continental margin. Episodes 22, 206216.

Campos Neto, O.P. de A., Lima, W.S., Gomes Cruz, F.E., 2007. Bacia de Sergipe-Alagoas. Bol. Geociencias da Petrobras 15, 405-415.

Cohen, J.K., Stockwell, J.J.W., 2013. CWP/SU: Seismic Un*x Release No. 43: an open source software package for seismic research and processing.

Cruz, L.R., Córdoba, V.C., Sá, E.F.J. de, 2010. Análise estratigráfica e evolução geodinâmica da 
"Sequência Transicional" na porção sul da Bacia de Sergipe-Alagoas. Bol. Geociências da Petrobras $18,31-49$.

Feijó, F.J., 1994. Bacia de Sergipe e Alagoas. Bol. Geociências da Petrobras 8, 149-161.

Fomel, S., Sava, P., Vlad, I., Liu, Y., Bashkardin, V., 2013. Madagascar: open-source software project for multidimensional data analysis and reproducible computational experiments. J. Open Res. Softw. 1, e8.

Hampson, D., 1986. Inverse velocity stacking for multiple elimination, in: SEG Technical Program Expanded Abstracts 1986. Society of Exploration Geophysicists, pp. 422-424.

Peacock, K.L., Treitel, S., 1969. PREDICTIVE DECONVOLUTION: THEORY AND PRACTICE. GEOPHYSICS 34, 155-169.

Schaller, H., 1969. Revisão estratigráfica da bacia de sergipe/alagoas. Bol. Técnico da Petrobras 12, 2186.

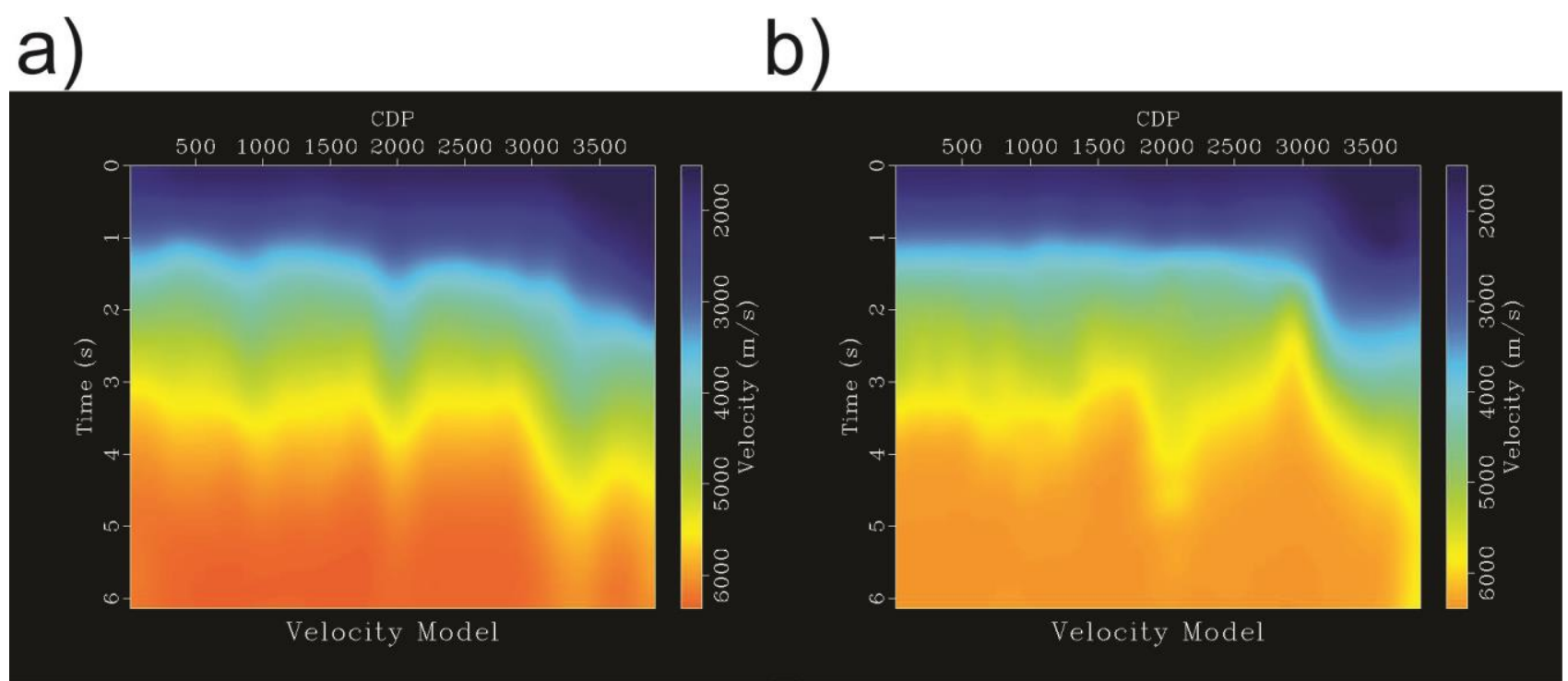

Figure 5 - Velocity model a) before and b) after PSTM.
Van Der Ven, P.H., Cainelli, C., Fernandes, G., 1989. Bacia de Sergipe-Alagoas: Geologia e Exploração. Bol. Geociências da Petrobras. 


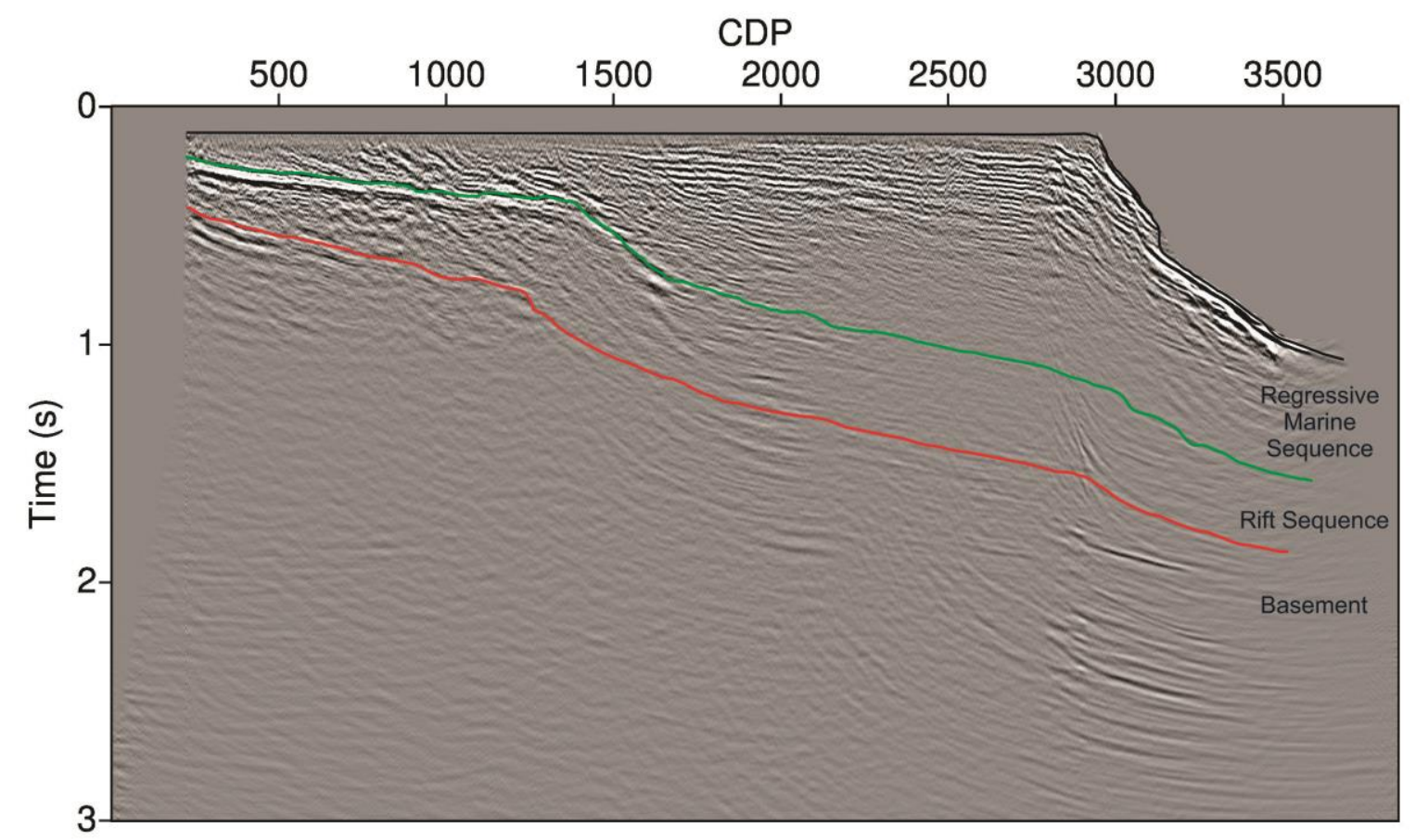

Figure 6 - Stacked section, result of the processing applied. The interpretation defines two main sequences: Rift and Regressive Marine. 